University of Wollongong

Research Online

Faculty of Engineering - Papers (Archive)

Faculty of Engineering and Information

Sciences

November 1998

\title{
Optimum design of absorber for MDOF structures
}

Muhammad N. S Hadi

University of Wollongong, mhadi@uow.edu.au

Y. Arfiadi

University of Wollongong

Follow this and additional works at: https://ro.uow.edu.au/engpapers

Part of the Engineering Commons

https://ro.uow.edu.au/engpapers/344

\section{Recommended Citation}

Hadi, Muhammad N. S and Arfiadi, Y.: Optimum design of absorber for MDOF structures 1998.

https://ro.uow.edu.au/engpapers/344

Research Online is the open access institutional repository for the University of Wollongong. For further information contact the UOW Library: research-pubs@uow.edu.au 


\title{
Optimum Design of Absorber for MDOF Structures
}

\author{
By Muhammad N. S. Hadi ${ }^{1}$ and Yoyong Arfiadi ${ }^{2}$
}

\begin{abstract}
This paper discusses the optimum design of tuned mass damper (TMD) for seismically excited building structures. In the design process the multi degree of freedom structures are considered so that it makes improvement to the available design procedures so far, where usually only single mode model is considered. The $\mathrm{H}_{2}$ norm of the transfer function from the extemal disturbance to a certain regulated output is taken as a performance measure of the optimization criterion. The genetic algorithm, which has been successfully applied in many applications, is used to find the optimum value of TMD parameters. The numerical examples for optimum parameters of TMD for multi degree of freedom structures are presented to show the effectiveness of this design procedure. It is shown that by using the proposed procedure, the optimum value of the mass damper can be determined without specifying the modes to be controlled. A comparison is also made to the Den Hartog and Warburton approaches.
\end{abstract}

\section{INTRODUCTION}

Although active vibration control nowadays has received considerable attention from many researchers, a passive control technique is still considered due to its simplicity. Moreover, many passive control devices have been successfully installed in the real building. The passive control devices which have been used are mainly base isolation, viscoelastic damper, and mass damper (absorber) system.

The use of absorber (tuned mass damper) to reduce the structural vibration has been studied because of its potential use. Tuned mass dampers have been used in the real application to reduce the lateral motion of high rise buildings (McNamara 1977; Wiesner 1986) as well as the vertical vibration of flexible floors (Webster and Vaicaitis 1992; Setareh and Hanson 1992a, 1992b).

In designing a TMD, several types of optimization procedures have been considered. Den Hartog (1956) has derived the formula for designing the optimum value of the absorber parameters, where the harmonic loading is applied to an undamped single-degree-of-freedom (SDOF) structure. An extension has been done in Warburton and Ayorinde (1980), Tsai (1993), and Tsai and Lin (1993), where a damping in the main mass is considered and several types of harmonic excitation are examined. Extensive research was also conducted by Warburton (1982) where formulas for several types of excitation were developed. In this case the harmonic and random excitations are applied either in the main system or at the base of the structure. In Warburton and Ayorinde (1980) and Warburton (1982), the analogy of multi-degree-of-freedom (MDOF) structure to the SDOF structure, such that the MDOF structure can be designed as an SDOF structure, was also outlined.

The study of the building utilizing mass damper under random loading that simulates the system subject to wind (McNamara 1977) and earthquake loading (Kaynia et al. 1981) has also been considered in the past. In this case, the building is modeled as an SDOF structure by transforming the structure into a modal coordinate of the dominant mode. Similarly, the study was carried out by Sadek et al. (1997) where the work of Villaverde (1985) was extended to find the tuning parameter by making the first two modes of the modal damping ratio

${ }^{1}$ Lect., Dept. of Civ., Mining, and Envir. Engrg., Univ. of Wollongong, Wollongong, NSW 2522, Australia. E-mail: m.hadi@uow.edu.au

${ }^{2}$ PhD Candidate, Dept. of Civ., Mining, and Envir. Engrg., Univ. of Wollongong, Wollongong, NSW 2522, Australia.

Note. Associate Editor: Chia-Ming Uang. Discussion open until April 1, 1999. To extend the closing date one month, a written request must be filed with the ASCE Manager of Journals. The manuscript for this paper was submitted for review and possible publication on September 5, 1997. This paper is part of the Journal of Structural Engineering, Vol. 124, No. 11, November, 1998. CASCE, ISSN 0733-9445/98/0011$1272-1280 / \$ 8.00+\$ .50$ per page. Paper No. 16596. equal. The extended procedure for MDOF structures is also based on the fundamental mode by making a modal participation factor at that mode to be one unit.

Other extensions are made by $\mathrm{Xu}$ and Igusa (1992), Yamaguchi and Harnpornchai (1993), and Kareem and Kline (1995), where the multituned mass damper is used to enhance the single TMD such that it can be tuned to several frequencies of interest. In those cases the SDOF structure is considered with several tuned mass dampers installed in parallel.

In this paper a TMD system is considered to be applied to MDOF structures, but without specifying which mode should be controlled. Therefore, there is no need to transfer the structure to a single-mode model as has been done in the available research.

Several cost or objective functions have been developed to meet a specified performance in the optimization process. In practice, many performance indices can be chosen, as the objective functions resulted in a different result of the optimization. In the active vibration control area, there are also many optimization criteria which have been used by researchers. These include linear quadratic regulator (Chang and Soong 1980), $\mathrm{H}_{2}$ (Suhardjo et al. 1992; Spencer et al. 1994) and $\mathrm{H}_{\infty}$ (Jabari et al. 1995) performance index, which minimize the structural responses while maintaining the control energy to be used in the practical range. While in the active control optimization there is a trade off between the response to be minimized and the expense of the control energy to be used, the passive control optimization is free from balancing the two parameters. In this case, the performance index used in the active control area is utilized. In fact, the procedure is effective for the passive control optimization as shown in Van de Vegte and Hladun (1973), Posbergh et al. (1991), Stech (1994), and Gluck et al. (1996).

In this paper, an $\mathrm{H}_{2}$ performance index is used. Since the disturbance in $\mathrm{H}_{2}$ optimization is a white noise with zero mean, consequently the external loading applied in the structure is considered as a white noise. Although according to $\mathrm{Xu}$ et al. (1992) and Xu and Kwok (1994) this assumption might not be appropriate for wind excitation, in practice $\mathrm{H}_{2}$ performance index has been utilized either for wind or earthquake loading in the literature (see Suhardjo et al. 1992; Spencer et al. 1994; Kareem and Kline 1995; Ankireddi and Yang 1997).

On the other hand, the use of genetic algorithm (GA) for solving the optimization problem has also been widely used by researchers and has been successfully applied to various problems (Goldberg 1989; Michalewicz 1996). In civil engineering applications, GA has been used to find the minimum weight of the structures (Jenkins 1991, 1997; Rajeev and Krishnamoorthy 1992) for static problems. In the area of active control GA has been used to determine the optimal location of the actuator for flexible structures (Rao et al. 1991). 
Considering its potential capability, the GA is utilized in this paper to find optimum parameters of the mass damper to be placed in the structural system, where $\mathbf{H}_{2}$ performance index is used as a criterion of the optimization procedure. Two numerical solutions were then carried out to the multistorey building utilizing mass damper subject to earthquake loading. Then, the response quantities were shown and comparisons were made to the available procedure to show the versatility of the $\mathrm{Ga}$ in solving the problem.

\section{EQUATION OF MOTION}

Consider an $\mathrm{N}$-storey shear building structure with mass damper installed at the top floor as shown in Fig. 1. The equations of motion of the structural system can be written as

$$
\mathbf{M} \ddot{\mathbf{X}}+\mathbf{C} \dot{\mathbf{X}}+\mathbf{K X}=\mathbf{F}+\mathbf{e} \ddot{x}_{g}
$$

where $\mathbf{M}, \mathbf{C}, \mathbf{K}$ are mass, damping, and stiffness matrices, respectively; F, e, and $\ddot{x}_{g}$ are the external force vector, matrix induced ground acceleration, and ground acceleration, respectively. The dot ( $)$ in the equation indicates a derivative with respect to time. The $\mathbf{M}, \mathbf{C}, \mathbf{K}$ matrices and $\mathbf{X}$ vector are summarized in Appendix $I$ for the detail.

The equations of motion can then be converted to a statespace equation as

$$
\dot{\mathbf{Z}}=\mathbf{A Z}+\mathbf{H F}+\mathbf{E} \boldsymbol{w}
$$

where

$$
\begin{gathered}
\mathbf{A}=\left[\begin{array}{cc}
\mathbf{0} & \mathbf{I} \\
-\mathbf{M}^{-1} \mathbf{K} & -\mathbf{M}^{-1} \mathbf{C}
\end{array}\right], \quad \mathbf{H}=\left[\begin{array}{c}
\mathbf{0} \\
\mathbf{M}^{-1}
\end{array}\right] \\
\mathbf{E}=\left\{\begin{array}{c}
\mathbf{0} \\
\mathbf{M}^{-1} \mathbf{e}
\end{array}\right\}, \quad \mathbf{Z}=\left\{\begin{array}{l}
\mathbf{X} \\
\dot{\mathbf{X}}
\end{array}\right\}, \quad w=\mathbf{x}_{g}
\end{gathered}
$$

Note that by transforming the equations of motion (1) to the state-space equation we have transformed the second-order differential equation to the first-order one. Note also that the size of the matrices in the state-space equation is 2 times larger than that of the ordinary equation of motion.

Since only earthquake loading is considered in this paper, the equations of motion can be written as

$$
\dot{\mathbf{Z}}=\mathbf{A Z}+\mathbf{E} \boldsymbol{w}
$$

The objective then is to find the optimum value of the mass damper parameters (i.e., mass, damping, and stiffness) that involve in $\mathbf{A}$.

Usually this problem is converted to a problem of SDOF structure where the parameter of the structure is at a specified mode (usually the first mode) to be chosen. In view of seeking a more realistic model, this paper used the MDOF model as a structural model. By considering the structure as an MDOF structure the optimization process becomes more difficult to solve. In this case, there is no closed-form solution available on such a case. Moreover, the closed-form solution to SDOF structures is available only in case there is no damping in the structure. In case of an inherent damping presence in the structure, the closed-form solution may not be available. Therefore, only numerical solution could be possible to solve the problem of MDOF structures with inherent damping.

\section{$\mathrm{H}_{2}$ OPTIMIZATION}

$\mathrm{H}_{2}$ optimization procedure has been considered to civil engineering application for the active control of buildings subjected to wind loading (Suhardjo et al. 1992) and earthquake excitation (Spencer et al. 1994). In this design strategy, the aim is to minimize the $\mathrm{H}_{2}$ norm of the transfer function of the closed loop system from the external disturbances to a certain

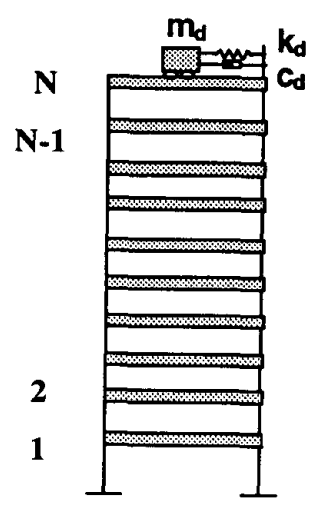

FIG. 1. NStorey Shear Bullding with TMD

controlled output. The external disturbance to be considered in $\mathrm{H}_{2}$ optimization is a unit intensity white noise with zero mean, while the controlled output can be chosen by the designer. The $\mathrm{H}_{2}$ norm can be determined by

$$
\left\|T_{r w}\right\|_{2}=\left(\frac{1}{2 \pi} \int_{-\infty}^{\infty} \operatorname{tr}\left(T_{r w}(j \omega) T_{r w}^{*}(j \omega) d \omega\right)\right)^{1 / 2}
$$

where $\left\|T_{n w}\right\|_{2}=\mathrm{H}_{2}$ norm transfer function from external disturbance $w$ to the controlled output $\mathbf{r} ; \omega=$ frequency; $j=$ imaginary; ${ }^{*}=$ complex conjugate transpose; and $\operatorname{tr}$ stands for the trace. put

For the system as in (2) with the regulated (controlled) out-

$$
\mathbf{r}=\mathbf{C}_{w} \mathbf{Z}
$$

the $\mathrm{H}_{2}$ norm transfer function from $w$ to $\mathbf{r}$ can be computed by (Lublin et al. 1996)

$$
\left\|T_{r w}\right\|_{2}=\left[\operatorname{tr}\left(\mathbf{C}_{w} \mathbf{L}_{c} \mathbf{C}_{w}^{T}\right)\right]^{1 / 2}=\left[\operatorname{tr}\left(\mathbf{E}^{T} \mathbf{L}_{o} \mathbf{E}\right)\right]^{1 / 2}
$$

where $\mathbf{L}_{c}$ and $\mathbf{L}_{o}$ are the controllability and the observability Gramians, respectively. $\mathbf{L}_{c}$ and $\mathbf{L}_{o}$ are the solutions of the Lyapunov equations

$$
\begin{gathered}
\mathbf{A L}_{c}+\mathbf{L}_{c} \mathbf{A}^{T}+\mathbf{E E ^ { T }}=\mathbf{0} \\
\mathbf{A}^{T} \mathbf{L}_{o}+\mathbf{L}_{o} \mathbf{A}+\mathbf{C}_{w}^{T} \mathbf{C}_{w}=\mathbf{0}
\end{gathered}
$$

Note that the regulated output in (6) can be taken as displacement, velocity, or acceleration. If the regulated output is taken as the relative displacement of floors with respect to the ground with the $\mathbf{X}$ vector taken as relative displacement with respect to the base, the matrix $\mathbf{C}_{w}$ can be written as

$$
\mathbf{C}_{w}=\left[\mathbf{I}_{N \times N} \mathbf{0}_{N \times(2(N+1)-N)}\right]
$$

where $\mathbf{I}=$ identity matrix; $\mathbf{0}=$ matrix contains zero; and $N=$ total degree of freedom of the original structure. It is also possible to choose the displacement, velocity, and acceleration at a certain floor as the regulated output. In this case the element matrix in $\mathbf{C}_{w}$ can be chosen accordingly.

The optimization problem is then to find the optimum of damper parameters that minimize (7) and the procedure of GA is used in this paper as an efficient tool.

\section{GENETIC ALGORITHM}

Genetic algorithm (GA) was developed by Holland and has been documented in his pioneering book in this area [Holland 1992 (first published 1975)]. The procedure of GA resembles the way living organisms survive in nature. It is so simple that GA has received a remarkable attention from researchers. GA searches the possible solution from many different points, such that it is easy to find a nearly global optimum solution. More- 


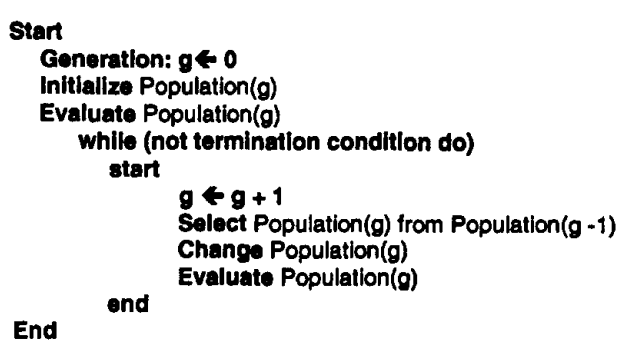

FIG. 2. Procedure of Genetic Algorithm

over, it does not need a gradient of the function to be optimized. The procedure is depicted in Fig. 2.

From an initial population, the individuals are selected based on a certain selection procedure. The selected individuals (parents) are then chosen randomly through crossover to produce offspring. The mutation procedure is then performed to maintain variability in the population. At the final stage (after performing selection, crossover, and mutation iteratively) the individual which has the best fitness is chosen as a design point.

Since GA works at a population size, its optimization can be considered as a stochastic optimization that starts from many different points. It is simple and does not need a gradient of the function. Every individual (chromosome) in the population is usually represented by a binary bit with a certain length. This chromosome can be converted to an integer value, and later its value can be transformed into a real number.

GA has been used in many applications as a function optimizer. Since GA is so efficacious in finding a nearly global optimum, as well as easy to use, researchers have used it in a variety of applications. In this paper GA was used for the vibration control of structure, where the objective function is the $\mathrm{H}_{2}$ norm of the transfer function from the external disturbance to the controlled output. For completeness, the procedure following Michalewicz (1996) is outlined in the following sections.

\section{Initial Population and Chromosome Representation}

GA starts from an initial population of chromosomes as initial design variables. The length of the bit (nbits) required to represent each variable can be determined by

$$
2^{(\text {nbits-1) }}<(U-L) \times 10^{p} \leq 2^{\text {nbits }}
$$

where $U=$ upper bound of a design variable, $L=$ lower bound of a design variable, and $p=$ required decimal precision. If the population is popsize, and the total number of bits (length of chromosome) is $l$, then for each chromosome (individual) in the population we must generate a random number $(0$ or 1$)$ as many as $l$. It is clear that the length of the chromosome depends on the required precision of the design variable. If higher precision is needed then the length of the chromosome is increased accordingly. Also, it should be noted here that GA searches the possible solution from several design points, such that it is easy for the GA to reach global optimum solution (Goldberg 1989).

\section{Fitness Evaluation}

Since an individual in the population for the next generation is selected based on its fitness value, then the fitness for each individual should be calculated, where the corresponding real value of the binary string is calculated using

$$
r_{x}=L+X^{*}(U-L) /\left(2^{\text {nbiss }}-1\right)
$$

in which $r_{x}$ and $X$ are real value and integer value of particular design variable, respectively. The value of $X$ can be obtained from relation

$$
X=\sum_{i=0}^{l m} b_{i} * 2^{i}
$$

where $b_{i}=$ binary bit $\left[b_{l m} b_{l m-1} \cdots b_{1} b_{0}\right]$; and $l_{m}=$ length of chromosome to represent a particular design variable -1 . This real value of design variables can then be substituted into the fitness function. Note also that in GA, the problem of the optimization is to maximize the fitness value such that in case of the problem of minimizing cost function the fitness value can be modified accordingly.

\section{Selection}

The selection procedure used by GA is based on the fitness of each chromosome. In this paper a roulette-wheel-based procedure is adopted as follows:

- Calculate the total fitness of the population using

$$
F=\sum_{k=1}^{\text {popsize }} \text { fitness }\left(r_{x, k}\right)
$$

where $F=$ total fitness of individual, and fitness $=$ fitness value of each individual.

- Calculate the probability of selection $p_{k}$ for each chromosome $(k=1,2, \ldots$, popsize $)$ by

$$
p_{k}=\frac{\text { fitness }\left(r_{x, k}\right)}{F}
$$

- Find the cumulative probabilities $q_{k}$ for each chromosome using

$$
q_{k}=\sum_{k=1}^{\text {popsize }} p_{k}
$$

- Spin the roulette wheel popsize times, where in each time select a single chromosome for a new population as follows:

1. generate popsize random numbers ( 0 or 1$) s_{k}, k=1,2$, ..., popsize.

2. if $s_{k}>q_{n-1}$ and $s_{k}<q_{n}, n=$ any number from 1 to popsize, then $q_{n}$ is selected in the new population.

\section{Crossover}

The crossover operator is used to produce an offspring from the selected parents. Suppose that from a population having 11 bits two parents are chosen for crossover. The crossover site was decided randomly. If the crossover site is between bits 4 and 5 , the first child will get the first four bits of chromosome from parent 1 and the last seven bits from parent 2 , while the second child will get the first four bits of chromosome from parent 2 and the last seven bits of chromosome from parent 1 . This procedure is shown diagrammatically in Fig. 3.

Since only selected parents undergo crossover, then it is necessary to build a procedure for crossover. For each chromosome in the new population, then, we can generate a random number $n_{c}$ from the range (0-1). If $n_{c}<p_{c}$, where $p_{c}$ is the probability of crossover, select a given chromosome for crossover.

\section{Mutation}

In order to maintain the variability of the population, a mutation should be performed in certain individuals. In this case, the mutation is performed on a bit-by-bit basis, with the probability of mutation $=p_{m}$. Therefore, there will be a total of 
Parent 1:

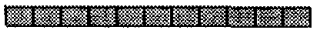

Parent 2:

\section{एTILTITITI}

Offspring 1:

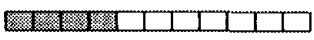

Orfspring 2:

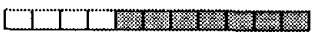

FIG. 3. Crossover Procedure: One-Point Crossover Slte between Bits 4 and 5

$\left\{p_{m} \times(\right.$ nbits $\times$ popsize $\left.)\right\}$ bits that undergo mutation. The mutation procedure can be performed by generating a random number $n_{r}$ from the range $(0-1)$. If $n_{r}<p_{m}$, mutate the bit, by changing 0 to 1 (or 1 to 0 ). The mutation procedure is shown diagrammatically in Fig. 4, representing a chromosome that undergoes mutation at bit positions 2 and 7 .

\section{APPLICATION}

\section{GA Parameters and Modification}

The parameters of GA to be used in this paper are taken as follows: population size $=30$; number of generation $=200$; probability of crossover $=0.45$; and probability of mutation $=$ 0.01 .

In this paper the standard procedure is slightly modified, where after performing selection, crossover, and mutation a number of new individuals are introduced, replacing older ones in the population. This step can be considered as increasing the variability in the population and exploring new candidates of the design points.

Moreover, an elitist strategy (Grefenstette 1986) is adopted where the best individual, i.e., the individual which has the highest fitness value, is always copied into the next generation. By copying the best individual into the next generation it is assured that the final generation will result in the best design point.

\section{Numerical Example 1}

A ten-storey shear building with the mass damper attached on the top floor is taken as an example. The building parameters are taken from Singh et al. (1997) with a slight modification, where $m_{1}=m_{2}=\cdots=m_{10}=360 \mathrm{t}, k_{1}=k_{2}=\cdots=k_{10}$ $=650 \mathrm{MN} / \mathrm{m}, c_{1}=c_{2}=\cdots=c_{10}=6.2 \mathrm{MN}-\mathrm{s} / \mathrm{m}$.

Suppose the mass of the damper is specified to be $m_{d}=0.3$ $m_{10}=0.03$ total mass of the building. The objective is to determine the optimum value of the stiffness $k_{d}$ and the damping $c_{d}$ of the damper that minimizes the $\mathrm{H}_{2}$ norm transfer function from the external disturbance to the regulated output. Suppose the regulated output that we want to minimize is the relative displacement of the structure with respect to the ground. According to (9) the regulated output is

$$
\mathbf{C}_{w}=\left[\begin{array}{ll}
\mathbf{I}_{10 \times 10} & \phi_{10 \times 12}
\end{array}\right]
$$

The GA procedure is then employed to optimize the TMD parameters where the stiffness and the damper of the TMD are chosen as design variables. The upper bound and the lower bound value of the stiffness are 0 and $4,000 \mathrm{kN} / \mathrm{m}$, while the upper bound and the lower bound of the damping are 0 and $1,000 \mathrm{kN}-\mathrm{s} / \mathrm{m}$, respectively. The length of the bits (chromosome) for the stiffness is taken as 16 , whereas the length of the bits for the damping is taken as 10 . In this case the binary

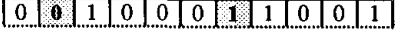

(a). Before mutation

\section{\begin{tabular}{|l|l|l|l|l|l|l|l|l|l|l|}
\hline 0 & 1 & 1 & 0 & 0 & 0 & 0 & 0 & 1 & 0 & 0
\end{tabular}}

(b). After mutation

\section{FIG. 4. Mutation Procedure}

bit represents the real value of one-digit precision for both stiffness and damping. By choosing this value the total length of the chromosome is to be 26. After performing the GA it is found that the optimum value of stiffness and damping of the TMD are $k_{d}=3,750 \mathrm{kN} / \mathrm{m}, c_{d}=151.5 \mathrm{kN}$-s $/ \mathrm{m}$ where the resulting damping ratio of TMD is $11.9 \%$. The evolving bestfitness generation per generation can be seen in Fig. 5 .

The top floor displacement of the building due to El Centro 1940 NS excitation is then plotted in Fig. 6. The peak responses of each floor are also presented in Table 1. From these simulation results, it can be said that for the building under consideration the reduction of about $30 \%$ can be achieved for peak displacement responses.

\section{Numerical Example 2}

As the second example, the 10-storey building with a TMD is taken from Sadek et al. (1997). The TMD has been optimized by Sadek et al. with the stiffness and mass properties as shown in Table 2, where the damping ratio of the first mode is $2 \%$. The mass of TMD is taken to be $0.05 \times$ first-mode modal mass, which gives a unit participation factor, i.e., $m_{d}=$ $0.05 \times 1,109 \mathrm{t}=55.45 \mathrm{t}$. The normalized mode shape of the first mode which gives the unit participation is as follows: $\left\{\phi_{1}\right\}^{T}=[0.175 ; 0.355 ; 0.534 ; 0.708 ; 0.871 ; 1.019 ; 1.146$; $1.248 ; 1.321$; and 1.359$]$ - where $\left\{\phi_{1}\right\}=1$ st mode shape of the structure (Sadek et al. 1997). The optimization was carried out by using a single-mode model, and the resulting optimum parameters are $\xi_{d}=0.3253$, with the tuning frequency $f=$ $\omega_{\text {TMD }} / \omega_{\text {structure }}=0.9302$, where in this case $c_{d}=104.4 \mathrm{kN}-\mathrm{s} / \mathrm{m}$, $k_{d}=464.1 \mathrm{kN} / \mathrm{m}$.

Before performing GA the damping matrix of the structure has to be determined. The damping in the structure is usually assumed to be Rayleigh (Clough and Penzien 1975) where the damping matrix is proportional to the stiffness and mass matrices, i.e., $\mathbf{C}=\alpha \mathbf{K}+\beta \mathbf{M}$, in which $\alpha$ and $\beta$ are constants. Since the available information in the Sadek et al. (1997) model is only related to the first mode, the damping matrix could be assumed either proportional to the stiffness or mass matrix. Therefore, two cases are considered, such that the procedure developed in this paper can be compared to the work of Sadek et al. The first case (case A) is where the damping matrix is in proportion to the stiffness matrix whereas the second case (case B) is where the damping is assumed to be proportional to the mass matrix. It is easy to show that $\mathbf{C}=$ $0.0129 \mathrm{~K}$; and $\mathrm{C}=0.1244 \mathrm{M}$ for cases $\mathrm{A}$ and $\mathrm{B}$ respectively.

The procedure of GA as in example 1 was then used to find the optimum parameters of TMD with no assumption on the model of the structure to be a single-mode model. The parameters used in GA procedures were taken to be the same as in numerical example 1, where the regulated output of the structures in this case was taken as the relative displacement of the floors with respect to the ground. It was found that the TMD parameters were $c_{d}=47.9 \mathrm{kN}-\mathrm{s} / \mathrm{m}$ and $k_{d}=437.9 \mathrm{kN} / \mathrm{m}$ for case A; and $c_{d}=48.9 \mathrm{kN}-\mathrm{s} / \mathrm{m}$ and $k_{d}=437.4 \mathrm{kN} / \mathrm{m}$ for case B. The evolving best fitness for these cases can be seen in Figs. 7 and 8.

For the sake of comparison, the approaches of Den Hartog (1956) and Warburton (1982) were also presented. The formula of Den Hartog was based on the SDOF undamped struc- 


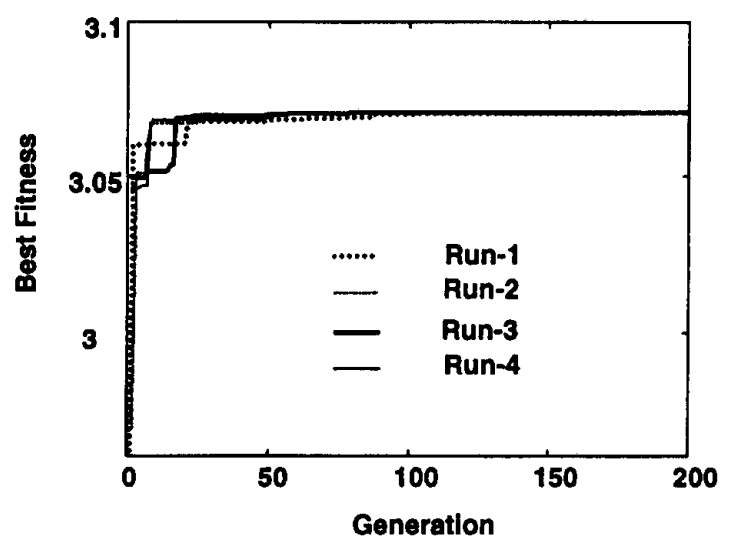

FIG. 5. Evolving Best Fitness of Example 1

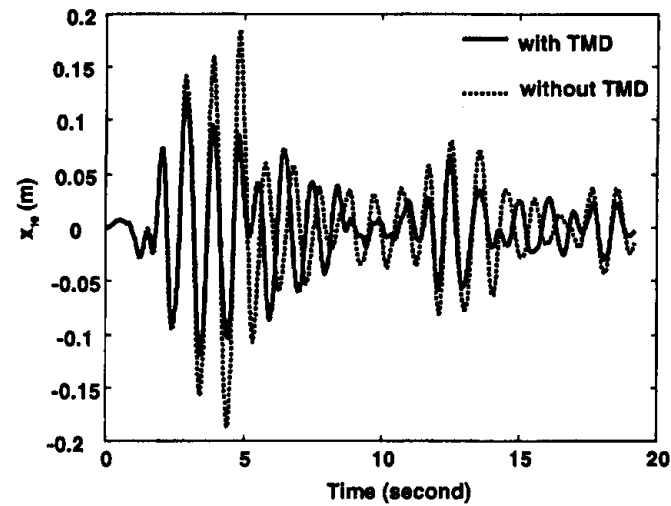

FIG. 6. Displacement of 10th Floor with Respect to Ground of Example 1

TABLE 1. Peak Responses of Example 1

\begin{tabular}{|c|c|c|c|c|}
\hline \multirow[b]{2}{*}{$\begin{array}{c}\text { Floor } \\
\text { (1) }\end{array}$} & \multicolumn{2}{|c|}{ With TMD } & \multicolumn{2}{|c|}{ Without TMD } \\
\hline & $\begin{array}{c}\text { Relative } \\
\text { displacement } \\
\text { (m) } \\
\text { (2) }\end{array}$ & $\begin{array}{l}\text { Absolute } \\
\text { acceleration } \\
\left(\mathrm{m} / \mathrm{s}^{2}\right) \\
(3)\end{array}$ & $\begin{array}{c}\text { Relative } \\
\text { displacement } \\
\text { (m) } \\
\text { (4) }\end{array}$ & $\begin{array}{c}\text { Absolute } \\
\text { acceleration } \\
\left(\mathrm{m} / \mathrm{s}^{2}\right) \\
(5)\end{array}$ \\
\hline $\begin{array}{c}1 \\
2 \\
3 \\
4 \\
5 \\
6 \\
7 \\
8 \\
9 \\
10 \\
\text { TMD }\end{array}$ & $\begin{array}{l}0.019 \\
0.037 \\
0.058 \\
0.068 \\
0.082 \\
0.094 \\
0.104 \\
0.113 \\
0.119 \\
0.122 \\
0.358\end{array}$ & $\begin{array}{r}2.698 \\
3.025 \\
3.528 \\
3.944 \\
4.079 \\
3.826 \\
4.390 \\
5.051 \\
5.534 \\
5.812 \\
13.942\end{array}$ & $\begin{array}{l}0.031 \\
0.060 \\
0.087 \\
0.112 \\
0.133 \\
0.151 \\
0.166 \\
0.177 \\
0.184 \\
0.188 \\
-\end{array}$ & $\begin{array}{l}2.903 \\
3.968 \\
4.950 \\
5.666 \\
6.155 \\
6.595 \\
6.735 \\
7.018 \\
7.834 \\
8.298 \\
-\end{array}$ \\
\hline
\end{tabular}

TABLE 2. Mass and Stiffness of Example 2

\begin{tabular}{|c|c|c|}
\hline $\begin{array}{c}\text { Floor } \\
\text { (1) }\end{array}$ & $\begin{array}{c}m_{i} \\
(t) \\
(2) \\
\end{array}$ & $\begin{array}{c}k_{i} \times 10^{3} \\
(\mathrm{kN} / \mathrm{m}) \\
(3)\end{array}$ \\
\hline $\begin{array}{r}10 \\
9 \\
8 \\
7 \\
6 \\
5 \\
4 \\
3 \\
2 \\
1\end{array}$ & $\begin{array}{r}98 \\
107 \\
116 \\
125 \\
134 \\
143 \\
152 \\
161 \\
170 \\
179\end{array}$ & $\begin{array}{l}34.31 \\
37.43 \\
40.55 \\
43.67 \\
46.79 \\
49.91 \\
53.02 \\
56.14 \\
52.26 \\
62.47\end{array}$ \\
\hline
\end{tabular}

ture with harmonic external load. According to Den Hartog the optimum tuning frequency ( $f o p t=\omega_{\mathrm{TMD}} / \omega_{\text {structure }}$ ) in terms of mass ratio $\mu$ can be expressed as

$$
f_{\text {opt }}=\frac{1}{1+\mu}
$$

whereas the optimum damping ratio of the damper $\xi_{\text {dopt }}$ is

$$
\xi_{\text {dopt }}=\sqrt{\frac{3 \mu}{8(1+\mu)}}
$$

The MDOF structure is then converted to SDOF structure following the procedure in Rana and Soong (1998) by normalizing the mode shape at the location of TMD to be 1 unit. Utilizing (17) and (18) we found that the optimum parameters are $c_{d}=56.2 \mathrm{kN}-\mathrm{s} / \mathrm{m}$ and $k_{d}=449.5 \mathrm{kN} / \mathrm{m}$.

Another approach to be compared here is according to Warburton (1982) where several design formulas have been derived for the optimum design of the absorber attached on SDOF undamped structures due to various types of external excitation. To facilitate comparison, the formula based on the white-noise excitation was taken. Based on this design, the optimum tuning frequency of the damper is

$$
f_{o p t}=\frac{1}{1+\mu} \sqrt{1-\mu / 2}
$$

and the optimum damping ratio of the damper is

$$
\xi_{\text {dopt }}=\sqrt{\frac{\mu(1-\mu / 4)}{4(1+\mu)(1-\mu / 2)}}
$$

Similar to the previous approach, the equivalent SDOF model was then determined and used to find the optimum parameters

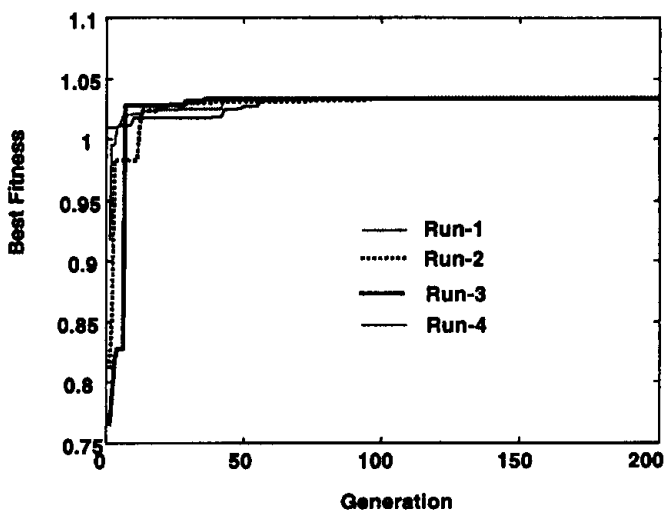

FIG. 7. Evolving Best Fitness of Example 2 Case A

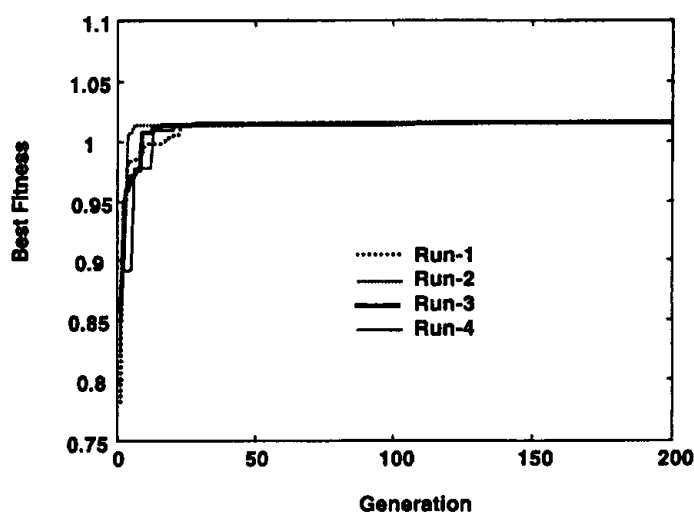

FIG. 8. Evolving Best Fitness of Example 2 Case B 
TABLE 3. Comparison Result of Example 2 Case A (Stiffness Proportional Damping)

\begin{tabular}{|c|c|c|c|c|c|c|c|c|c|c|}
\hline \multirow[b]{2}{*}{$\begin{array}{c}\text { Floor } \\
\text { (1) }\end{array}$} & \multicolumn{2}{|c|}{ Den Hartog 1956} & \multicolumn{2}{|c|}{ Warburton 1982} & \multicolumn{2}{|c|}{ Sadek et al. 1997} & \multicolumn{2}{|c|}{ Present Approach } & \multicolumn{2}{|c|}{ Uncontrolled } \\
\hline & $\begin{array}{l}\text { Relative } \\
\text { displace- } \\
\text { ment } \\
(\mathrm{m}) \\
(2)\end{array}$ & \begin{tabular}{|c|} 
Absolute \\
acceleration \\
$\left(\mathrm{m} / \mathrm{s}^{2}\right)$ \\
$(3)$
\end{tabular} & $\begin{array}{c}\text { Relative } \\
\text { displace- } \\
\text { ment } \\
\text { (m) } \\
(4)\end{array}$ & $\begin{array}{c}\text { Absolute } \\
\text { acceleration } \\
\left(\mathrm{m} / \mathrm{s}^{2}\right) \\
(5)\end{array}$ & $\begin{array}{c}\text { Relative } \\
\text { displace- } \\
\text { ment } \\
(\mathrm{m}) \\
(6)\end{array}$ & $\begin{array}{c}\text { Absolute } \\
\text { acceleration } \\
\left(\mathrm{m} / \mathrm{s}^{2}\right) \\
(7) \\
\end{array}$ & $\begin{array}{c}\text { Relative } \\
\text { displace- } \\
\text { ment } \\
(\mathrm{m}) \\
(\mathrm{B})\end{array}$ & $\begin{array}{c}\text { Absolute } \\
\text { acceleration } \\
\left(\mathrm{m} / \mathrm{s}^{2}\right) \\
(9)\end{array}$ & $\begin{array}{c}\text { Relative } \\
\text { displace- } \\
\text { ment } \\
(\mathrm{m}) \\
(10)\end{array}$ & $\begin{array}{c}\text { Absolute } \\
\text { acceleration } \\
\left(\mathrm{m} / \mathrm{s}^{2}\right) \\
(11)\end{array}$ \\
\hline 1 & 0.034 & 3.049 & 0.036 & 3.077 & 0.036 & 3.060 & 0.034 & 3.048 & 0.041 & 3.056 \\
\hline 2 & 0.074 & 2.636 & 0.079 & 2.695 & 0.077 & 2.659 & 0.072 & 2.632 & 0.088 & 2.766 \\
\hline 3 & 0.106 & 2.764 & 0.114 & 2.750 & 0.113 & 2.713 & 0.105 & 2.778 & 0.129 & 2.977 \\
\hline 4 & 0.136 & 2.707 & 0.147 & 2.727 & 0.145 & 2.717 & 0.134 & 2.704 & 0.166 & 2.755 \\
\hline 5 & 0.163 & 2.678 & 0.177 & 2.671 & 0.172 & 2.693 & 0.160 & 2.673 & 0.197 & 2.933 \\
\hline 6 & 0.187 & 2.878 & 0.206 & 2.921 & 0.194 & 2.953 & 0.184 & 2.853 & 0.222 & 3.136 \\
\hline 7 & 0.213 & 2.365 & 0.236 & 2.426 & 0.219 & 2.454 & 0.210 & 2.336 & 0.252 & 2.922 \\
\hline 8 & 0.239 & 2.711 & 0.267 & 2.913 & 0.245 & 2.713 & 0.236 & 2.696 & 0.286 & 3.675 \\
\hline 9 & 2.612 & 3.222 & 0.292 & 3.443 & 0.266 & 3.251 & 0.258 & 3.199 & 0.313 & 4.697 \\
\hline 10 & 0.276 & 3.876 & 0.310 & 4.129 & 0.281 & 3.989 & 0.272 & 3.855 & 0.327 & 5.363 \\
\hline TMD & 0.602 & 4.792 & 0.751 & 5.707 & 0.456 & 3.744 & 0.635 & 5.003 & - & - \\
\hline
\end{tabular}

TABLE 4. Comparison Result of Example 2 Case B (Mass Proportional Damping)

\begin{tabular}{|c|c|c|c|c|c|c|c|c|c|c|}
\hline \multirow[b]{2}{*}{$\begin{array}{c}\text { Floor } \\
\text { (1) }\end{array}$} & \multicolumn{2}{|c|}{ Den Hartog 1956} & \multicolumn{2}{|c|}{ Warburton 1982} & \multicolumn{2}{|c|}{ Sadek et al. 1997} & \multicolumn{2}{|c|}{ Present Approach } & \multicolumn{2}{|c|}{ Uncontrolled } \\
\hline & $\begin{array}{l}\text { Relative } \\
\text { displace- } \\
\text { ment } \\
(\mathrm{m}) \\
(2)\end{array}$ & \begin{tabular}{|c|} 
Absolute \\
acceleration \\
$\left(\mathrm{m} / \mathrm{s}^{2}\right)$ \\
$(3)$
\end{tabular} & $\begin{array}{l}\text { Relative } \\
\text { displace- } \\
\text { ment } \\
(\mathrm{m}) \\
(4)\end{array}$ & \begin{tabular}{|c} 
Absolute \\
acceleration \\
$\left(\mathrm{m} / \mathrm{s}^{2}\right)$ \\
$(5)$
\end{tabular} & $\begin{array}{c}\text { Relative } \\
\text { displace- } \\
\text { ment } \\
(m) \\
(6)\end{array}$ & $\begin{array}{c}\text { Absolute } \\
\text { acceleration } \\
\left(\mathrm{m} / \mathrm{s}^{2}\right) \\
(7)\end{array}$ & $\begin{array}{l}\text { Relative } \\
\text { displace- } \\
\text { ment } \\
(\mathrm{m}) \\
(8)\end{array}$ & $\begin{array}{c}\text { Absolute } \\
\text { acceleration } \\
\left(\mathrm{m} / \mathrm{s}^{2}\right) \\
(9)\end{array}$ & $\begin{array}{c}\text { Relatlve } \\
\text { displace- } \\
\text { ment } \\
(\mathrm{m}) \\
(10)\end{array}$ & $\begin{array}{c}\text { Absolute } \\
\text { acceleration } \\
\left(\mathrm{m} / \mathrm{s}^{2}\right) \\
(11)\end{array}$ \\
\hline 1 & 0.040 & 5.476 & 0.043 & 5.609 & 0.039 & 4.938 & 0.040 & 5.613 & 0.052 & 6.369 \\
\hline 2 & 0.077 & 5.938 & 0.083 & 6.026 & 0.078 & 5.568 & 0.076 & 6.007 & 0.010 & 6.825 \\
\hline 3 & 0.106 & 5.490 & 0.115 & 5.627 & 0.109 & 5.330 & 0.104 & 5.525 & 0.130 & 6.367 \\
\hline 4 & 0.131 & 4.570 & 0.142 & 4.609 & 0.144 & 4.500 & 0.128 & 4.586 & 0.168 & 4.860 \\
\hline 5 & 0.166 & 5.725 & 0.179 & 5.707 & 0.181 & 5.708 & 0.162 & 5.719 & 0.207 & 6.782 \\
\hline 6 & 0.195 & 7.435 & 0.210 & 7.577 & 0.210 & 7.225 & 0.190 & 7.459 & 0.242 & 8.461 \\
\hline 7 & 0.207 & 5.904 & 0.226 & 6.096 & 0.224 & 5.738 & 0.201 & 5.924 & 0.254 & 6.597 \\
\hline 8 & 0.233 & 6.242 & 0.259 & 6.292 & 0.242 & 6.131 & 0.230 & 6.253 & 0.279 & 6.557 \\
\hline 9 & 0.272 & 6.809 & 0.302 & 7.071 & 0.278 & 6.638 & 0.269 & 6.825 & 0.316 & 7.339 \\
\hline 10 & 0.298 & 8.804 & 0.332 & 9.263 & 0.302 & 8.546 & 0.294 & 8.844 & 0.343 & 9.741 \\
\hline TMD & 0.605 & 5.099 & 0.753 & 5.793 & 0.461 & 4.279 & 0.632 & 5.199 & - & - \\
\hline
\end{tabular}

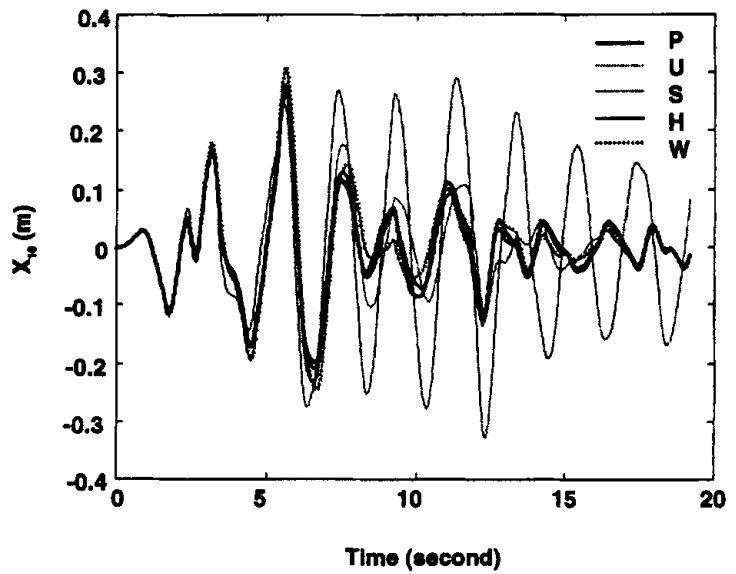

FIG. 9. Displacement of 10th Floor with respect to Ground of Example 2 Case A: P = Present Work; $U=$ Uncontrolled; $\mathbf{S}=\mathbf{S a -}$ dek et al.; $H=$ Den Hartog, $W=$ Warburton

of TMD. The results are $c_{d}=45.5 \mathrm{kN}-\mathrm{s} / \mathrm{m}$ and $k_{d}=428.7$ $\mathrm{kN} / \mathrm{m}$.

The numerical comparison was then carried out subject to El Centro 1940 NS excitation. Peak responses are presented in Tables 3 and 4 for case A and B, respectively. The responses are also plotted as shown in Figs. 9-12 comparing the results of different approaches. Note also in this case that in the beginning the response of the structure is almost similar for all cases.
From these simulation results it can be seen that the approach developed in this paper agrees well with Den Hartog's approximation, while the result of the Warburton approximation is slightly different from the present paper. It is to be noted also that, although the response of the structure by Sadek et al. approximation agrees well with the proposed procedure, the optimized damper parameters are slightly greater than in the present approach. Comparing the simulation results it can be seen that the response using the approach developed in this paper results in a smaller response compared to other ap-

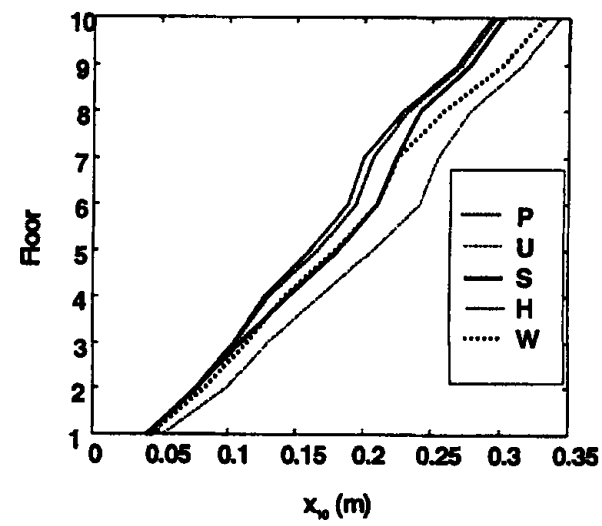

FIG. 10. Peak Response of 10th Dlsplacement with respect to Ground Case A: P = Present Work; U = Uncontrolled; $\mathbf{S}=$ Sadek et al.; $H=$ Den Hartog; $W=$ Warburton 


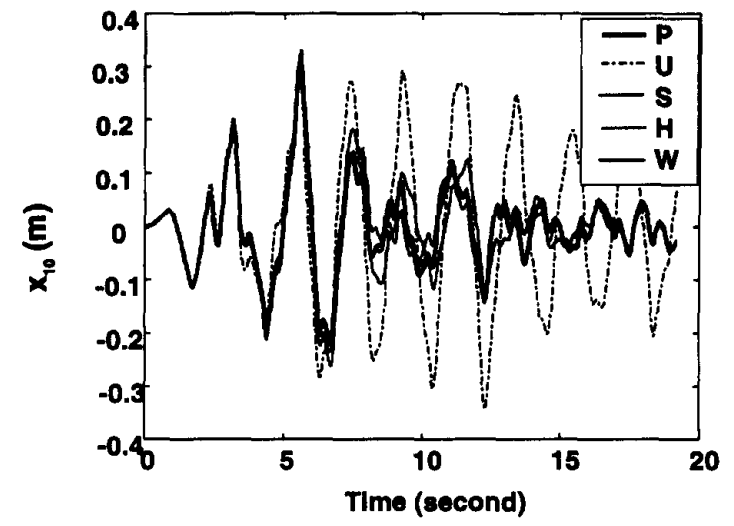

FIG. 11. Displacement of 10th Floor with respect to Ground of Example 2 Case B: P = Present Work; U = Uncontrolled; S = Sadek et al.; $H$ = Den Hartog; $W$ = Warburton

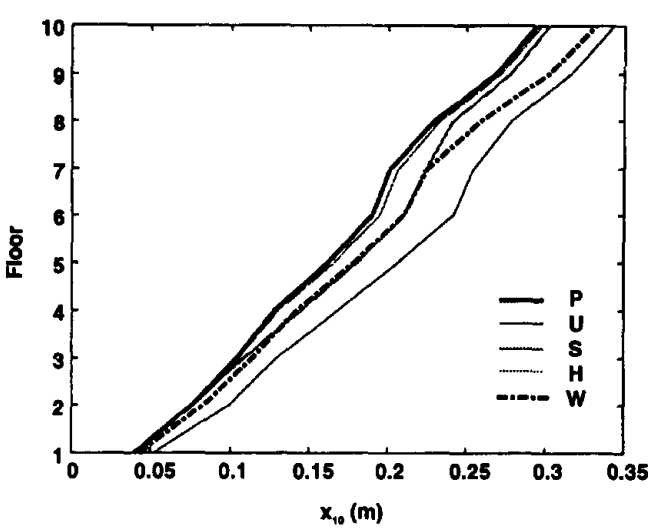

FIG. 12. Peak Response of 10th Displacement with respect to Ground Case B: $\mathbf{P}=$ Present Work; $\mathbf{U}=$ Uncontrolled; $\mathbf{S}=$ Sadek et al.; H = Den Hartog; $W=$ Warburton

proaches with the reduction of displacement response of about $15 \%$.

\section{CONCLUSIONS}

The optimum parameters of the TMD have been discussed in this paper. It should be noted that no assumption is made to reduce the MDOF model to a single-mode model. Therefore, the procedure used in this paper can be said to be more general than the available numerical models so far.

In this paper, GA has been used to optimize the parameters of mass damper for MDOF structures. The procedures of GA are modified, where after performing selection, mutation, and crossover, a number of new individuals is introduced, replacing some individuals in the population. This procedure can be considered for increasing the variability of the population and avoiding the convergence into local optima. Moreover, an elitist strategy is also used in this paper, where the best-fitness individual is always copied into the next generation.

From the numerical results of the building subjected to ElCentro 1940 NS excitation, it can be said that the TMD system is quite effective in reducing the vibration response. From numerical example 1, it was found that the peak building response is reduced with the reduction of about $30 \%$. In numerical example 2 the result of the proposed procedure is compared to the one of Den Hartog (1956), Warburton (1982), and Sadek et al. (1997). It was found that the response using the proposed procedure is smaller than other approximation procedures, with the possible reduction of about $15 \%$. It is noted that the result of the proposed procedure agrees well with Den Hartog's approach. Also, that in the beginning excitation the responses of the structure are very similar. This is because the TMD needs time before it can react effectively to external load (see Kobori et al. 1991). To enhance the TMD effectiveness, active control may be introduced to the structural system.

\section{APPENDIXI. MATRICES IN EQUATIONS OF MOTION}

If the $\mathbf{X}$ in (1) is taken as the relative displacement with respect to the ground, then the matrices to be used in (1) are as follows:

$$
\mathbf{M}=\operatorname{diag}\left[m_{1} \quad m_{2} \cdots m_{N} \quad m_{d}\right]
$$

$$
\mathbf{C}=\left[\begin{array}{ccccccc}
\left(c_{1}+c_{2}\right) & -c_{2} & & & & & \\
-c_{2} & \left(c_{2}+c_{3}\right) & -c_{3} & & & & \\
& & \cdot & \cdot & & & \\
& & \cdot & \cdot & \cdot & & \\
& & & \cdot & \cdot & \cdot & \\
& & & & -c_{N} & \left(c_{N}+c_{d}\right) & -c_{d} \\
& & & & & -c_{d} & c_{d}
\end{array}\right]
$$

$$
\mathbf{K}=\left[\begin{array}{ccccccc}
\left(k_{1}+k_{2}\right) & -k_{2} & & & & & \\
-k_{2} & \left(k_{2}+k_{3}\right) & -k_{3} & & & & \\
& & \cdot & \cdot & & & \\
& & \cdot & \cdot & \cdot & & \\
& & & \cdot & \cdot & \cdot & \\
& & & & -k_{N} & \left(k_{N}+k_{d}\right) & -k_{d} \\
& & & & & -k_{d} & k_{d}
\end{array}\right]
$$

$$
\begin{gathered}
\mathbf{X}=\left[\begin{array}{cccc}
x_{1} & x_{2} \cdots & x_{N} & x_{d}
\end{array}\right]^{T} \\
\mathbf{F}=\left[\begin{array}{lllll}
f_{1} & f_{2} & \cdots & f_{N} & f_{d}
\end{array}\right]^{T} \\
\mathbf{e}=\left[\begin{array}{lllll}
-m_{1} & -m_{2} & \cdots & -m_{N} & -m_{d}
\end{array}\right]^{T}
\end{gathered}
$$

where $m_{i}=$ mass of $i$ th floor $(i=1,2, \ldots, N) ; m_{d}=$ mass of damper; $c_{i}=$ damping of $i$ th floor $(i=1,2, \ldots, N) ; c_{d}=$ damping of the damper; $k_{i}=$ stiffness of $i$ th storey $(i=1,2$, $\ldots, N) ; k_{d}=$ stiffness of the damper; $x_{i}=$ displacement of $i$ th floor relative to ground $(i=1,2, \ldots, N) ; x_{d}=$ displacement of damper relative to ground; $f_{i}=$ external force applied at $i$ th floor; $f_{d}=$ external force applied at the absorber; and $x_{g}=$ ground displacement due to earthquake.

If $\mathbf{X}$ is defined as the storey drift vector then

$$
\begin{aligned}
\mathbf{M} & =\left[\begin{array}{ccccccc}
m_{1} & 0 & 0 & \cdot & \cdot & \cdot & 0 \\
m_{2} & m_{2} & 0 & 0 & \cdot & \cdot & 0 \\
\cdot & \cdot & \cdot & \cdot & \cdot & \cdot & \cdot \\
\cdot & \cdot & \cdot & \cdot & \cdot & \cdot & \cdot \\
\cdot & \cdot & \cdot & \cdot & \cdot & \cdot & \cdot \\
m_{N} & m_{N} & \cdot & \cdot & \cdot & m_{N} & 0 \\
m_{d} & m_{d} & \cdot & \cdot & \cdot & \cdot & m_{d}
\end{array}\right] \\
\mathbf{C} & =\left[\begin{array}{ccccccc}
c_{1} & -c_{2} & 0 & 0 & \cdot & \cdot & 0 \\
0 & c_{2} & -c_{3} & 0 & \cdot & \cdot & 0 \\
\cdot & \cdot & \cdot & \cdot & \cdot & \cdot & \cdot \\
\cdot & \cdot & \cdot & \cdot & \cdot & \cdot & \cdot \\
\cdot & \cdot & \cdot & \cdot & \cdot & \cdot & \cdot \\
0 & 0 & \cdot & \cdot & \cdot & c_{N} & -c_{d} \\
0 & 0 & \cdot & \cdot & \cdot & 0 & c_{d}
\end{array}\right]
\end{aligned}
$$




$$
\begin{array}{r}
\mathbf{K}=\left[\begin{array}{ccccccc}
k_{1} & -k_{2} & 0 & 0 & \cdot & \cdot & 0 \\
0 & k_{2} & -k_{3} & 0 & \cdot & \cdot & 0 \\
\cdot & \cdot & \cdot & \cdot & \cdot & \cdot & \cdot \\
\cdot & \cdot & \cdot & \cdot & \cdot & \cdot & \cdot \\
\cdot & \cdot & \cdot & \cdot & \cdot & \cdot & \cdot \\
0 & 0 & \cdot & \cdot & \cdot & k_{N} & -k_{d} \\
0 & 0 & \cdot & \cdot & \cdot & 0 & k_{d}
\end{array}\right] \\
\quad \mathbf{X}=\left[\begin{array}{llllll}
y_{1} & y_{2} & \cdots & y_{N} & y_{d}
\end{array}\right]^{T}
\end{array}
$$

where $y_{i}=i$ th storey drift, $y_{d}=$ relative displacement of TMD with respect to $N$ th floor.

\section{ACKNOWLEDGMENT}

The junior writer appreciates the financial support from Atma Jaya Yogyakarta University, Indonesia, that makes him able to carry out the research at the University of Wollongong.

\section{APPENDIX II. REFERENCES}

Ankireddi, S., and Yang, H. T. Y. (1997). "Multiple objective LQG control of wind-excited buildings." J. Struct. Engrg., ASCE, 123(7), 943-951

Chang, J. C. H., and Soong, T. T. (1980). "Structural control using active tuned mass dampers." J. Engrg. Mech., ASCE, 106(6), 1091-1098.

Clough, R. W., and Penzien, J. (1975). Dynamics of structures. McGrawHill, Kogakusha, Tokyo, Japan.

Den Hartog, J. P. (1956). Mechanical vibration. McGraw-Hill, New York.

Gluck, N., Reinhorn, A. M., Gluck, J., and Levy, R. (1996). "Design of supplemental damper for control of structures." J. Struct. Engrg., ASCE, 122(12), 1394-1399.

Goldberg, D. E. (1989). Genetic algorithms in search, optimization and machine learning. Addison-Wesley Publishing Co., Inc., Reading, Mass.

Grefenstette, J. J. (1986). "Optimization of control parameters for genetic algorithms." IEEE Trans. on System, Man and Cybernetics, SMC$16(1), 122-128$.

Holland, J. H. (1992). Adaptation in natural and artificial systems. MIT Press, Cambridge, Mass.

Jabbari, F., Schmitendorf, W. E., and Yang, J. N. (1995). " $\mathrm{H}_{\infty}$ control for seismic-excited buildings with acceleration feedback." J. Engrg. Mech., ASCE, 121(9), 994-1002.

Jenkins, W. M. (1991). "Towards structural optimization via the genetic algorithm." Comp. and Struct., 40(5), 1321-1327.

Jenkins, W. M. (1997). "On the application of natural algorithms to structural design optimization." Engrg. Struct., 19(4), 302-308.

Kareem, A., and Kline, S. (1995). "Performance of multiple tuned mass dampers under random loading." J. Struct. Engrg., ASCE, 121(2), $348-361$.

Kaynia, A. M., Veneziano, D., and Biggs, J. M. (1981). "Seismic effectiveness of tuned mass dampers." J. Struct. Div., ASCE, 107(8), $1465-1484$.

Kobori, T., Koshika, N., Kazuhiko, Y., and Ikeda, Y. (1991). "Seismicresponse-control structure with active mass driver system. Part 1: design." Earthquake Engrg. and Struct. Dynamics, 20, 135-149.

Lublin, L., Grocott, S., and Athans, M. (1996). " $\mathrm{H}_{2}(\mathrm{LQG})$ and $\mathrm{H}_{\infty}$ control." The control handbook, W. S. Levin, ed. CRC Press, Inc., Boca Raton, Fla.

McNamara, R. J. (1977). "Tuned mass damper for building." J. Struct. Div., ASCE, 103(9), 1785-1797.

Michalewicz (1996). Genetic algorithms + data structures $=$ evolution program. Springer-Verlag, Berlin, Germany.

Posbergh, T. A., Trimboli, M. S., and Duke, J. P. (1991). "A control formulation for vibration absorbers." Proc., Am. Control Conf., American Automatic Control Council, 3, 2481-2482. Boston, Mass.

Rajeev, S., and Krishnamoorthy, C. S. (1992). "Discrete optimization of structures using genetic algorithms." J. Struct. Engrg., ASCE, 118(5) $1233-1250$.

Rana, R., and Soong, T. T. (1998). "Parametric study and simplified design of tuned mass dampers." Engrg. Struct., 20(3), 193-204.

Rao, S. S., Pan, T. S., and Venkayya, V. B. (1991). "Optimal placement of actuators in actively controlled structures using genetic algorithms.' AIAA J., American Inst. of Aeronautics and Astronautics, Washington, D.C., 29(6), 942-943.

Sadek, F., Mohraj, B., Taylor, A. W., Chung, R. M. (1997). "A method of estimating the parameters of tuned mass dampers for seismic application." Earthquake Engrg. and Struct. Dynamics, 26, 617-635.
Setareh, M., and Hanson, R. D. (1992a). "Tuned mass damper for balcony vibration control." J. Struct. Engrg., ASCE, 118(3), 723-740.

Setareh, M., and Hanson, R. D. (1992b). "Tuned mass damper to control vibration from humans." J. of Struct. Engrg., ASCE, 118(3), 741-761.

Singh, M. P., Matheu, E. E., and Suarez, L. E. (1997). "Active and semiactive control of structures under seismic excitation." Earthquake Engrg. and Struct. Dymamics, 26, 193-213.

Spencer, B. F. Jr., Suhardjo, J., and Sain, M. K. (1994) "Frequency domain optimal control strategies for aseismic protection." J. Engrg. Mech., ASCE, 120(1), 135-158.

Stech, D. J. (1994). " $\mathrm{H}_{2}$ approach for optimally tuning passive vibration absorbers to flexible structures." $J$. Guidance, Contr. and Dynamics, 17(3), 636-638.

Suhardjo, J., Spencer B. F. Jr., and Kareem, A. (1992). "Frequency domain optimal control of wind-excited buildings." J. Engrg. Mech. ASCE, 118(12), 2463-2481.

Tsai, H. C. (1993). "Green's function of support-excited structures with tuned-mass dampers derived by a perturbation method." Earthquake Engrg. Struct. Dynamics, 22, 975-990.

Tsai, H. C., and Lin, G. C. (1993). "Optimum tuned-mass dampers for minimizing steady-state response of support-excited and damped systems." Earthquake Engrg. Struct. Dynamics, 22 957-973.

Van de Vegte, J., and Hladun, A. R. (1973). "Design of optimal passive vibration controls by optimal techniques." J. Dynamic Systems Measurement and Control, 427-434.

Villaverde, R. (1985). "Reduction in seismic response with heavilydamped vibration absorbers." Earthquake Engrg. Struct. Dynamics, 13 33-42.

Warburton, G. B. (1982). "Optimum absorbers parameters for various combinations of response and excitation." Earthquake Engrg. Struct. Dynamics, 10, 381-401

Warburton, G. B., and Ayorinde, E. O. (1980). "Optimum absorber parameters for simple systems." Earthquake Engrg. Struct. Dynamics, 8, 197-217.

Webster, A. C., and Vaicaitis, R. (1992). "Application of tuned mass dampers to control vibration of composite floor systems." Engrg. J. American Inst. of Steel Construction, 29(3), 116-124.

Wiesner, K. B. (1986). "Taming lively buildings." Civ. Engrg., June, $54-57$.

Xu, Y. L., Kwok, K. C. S., and Samali, B. (1992). "Control of windinduced tall building vibration by tuned mass dampers." $J$. Wind Engrg. Ind. Aerodyn., 40, 1-32.

Xu, Y. L., and Kwok, K. C. S. (1994). "Semianalytical method for parametric study of tuned mass dampers." J. Struct. Engrg., 120(3), $747-764$.

Xu, K., and Igusa, T., (1992). "Dynamic characteristics of multiple substructures under closely spaced frequencies." Earthquake Engrg. and Struct. Dynamics, 21, 1059-1070.

Yamaguchi, H., and Harnpornchai, N. (1993). "Fundamental characteristics of multiple tuned mass dampers for suppressing harmonically forced oscillation." Earthquake Engrg. and Struct. Dynamics, 22, $51-62$

\section{APPENDIX III. NOTATION}

The following symbols are used in this paper:

$\mathbf{A}=$ state matrix of system;

$\mathbf{C}=$ damping matrix;

$\mathbf{C}_{w}=$ matrix relates regulated output and state vector;

$c_{d}=$ damping of absorber;

$c_{i}=$ damping of $i$ th storey $(i=1,2, \ldots, N)$;

$\mathbf{E}=$ induced disturbance to state system;

$\mathbf{e}=$ influence matrix of earthquake to structure;

$F=$ total fitness of individual;

$\mathbf{F}=$ external load vector;

$f=$ frequency tuning ratio;

$f_{d}=$ external load applied at absorber;

$f_{i}=$ external load applied at $i$ th floor $(i=1,2, \ldots, N)$;

$\mathbf{H}=$ location matrix of external load;

$\mathbf{I}=$ matrix identity;

$\mathbf{K}=$ stiffness matrix;

$k_{d}=$ stiffness of absorber;

$k_{i}=$ stiffness of $i$ th storey $(i=1,2, \ldots, N)$;

$L=$ lower bound of design variable;

$\mathbf{L}_{c}=$ controllability Gramian matrix;

$\mathbf{L}_{o}=$ observability Gramian matrix; 
$l=$ length of chromosome;

$l_{m}=$ length of chromosome to represent particular design variable -1

$\mathbf{M}=$ mass matrix

$m_{d}=$ mass of absorber;

$m_{i}=$ mass of $i$ th floor $(i=1,2, \ldots, N)$;

$N=$ total number degree of freedom of main structure;

nbits = length of chromosome;

$p=$ decimal precision;

$p_{k}=$ probability of selection of each chromosome;

popsize $=$ population size;

$q_{k}=$ cumulative probability of selection for each chromosome;

$\mathbf{r}=$ regulated output;

$r_{x}=$ real value of variable;

$T_{n}=$ transfer function from $w$ to $\mathbf{r}$;

$U=$ upper bound of design variable;
$X=$ integer value of design variable;

$\mathbf{X}=$ displacement vector or storey drift vector defined in Appendix I;

$x_{d}=$ relative displacement of absorber with respect to ground;

$x_{g}=$ ground displacement due to earthquake;

$x_{i}=$ relative displacement of $i$ th floor with respect to ground $(i=1,2, \ldots, N)$;

$y_{i}=i$ th storey drift;

$\mathbf{Z}=$ state variable;

$\alpha=$ damping proportional to stiffness;

$\beta=$ stiffness constant proportional to mass;

$\phi=$ mode shape;

$\mu=$ mass ratio;

$\omega=$ natural frequency; and

$\xi=$ damping ratio. 